\title{
A Review of Methods Used to Reduce the Effects of High Temperature Associated with Polyamide 12 and Polypropylene Laser Sintering
}

\author{
Fredrick M. Mwania ${ }^{D}$, Maina Maringa, and Kobus van der Walt \\ Department of Mechanical and Mechatronics Engineering, Central University of Technology, Private Bag X20539, Bloemfontein, \\ Free State 9300, South Africa
}

Correspondence should be addressed to Fredrick M. Mwania; fredmulinge@gmail.com

Received 4 May 2020; Revised 9 July 2020; Accepted 20 July 2020; Published 4 August 2020

Academic Editor: Bingang Xu

Copyright (c) 2020 Fredrick M. Mwania et al. This is an open access article distributed under the Creative Commons Attribution License, which permits unrestricted use, distribution, and reproduction in any medium, provided the original work is properly cited.

\begin{abstract}
The polymer laser sintering (PLS) process is one of the most promising additive manufacturing (AM) technologies for polymeric materials. However, the technique has challenges because the physical, mechanical, and chemical properties of the polymeric powder deteriorate due to the high temperatures prevailing in the build chamber during manufacture. These high temperatures cause agglomeration of powder, which leads to a decrease in the flowability of powder. There is also a related drop in the coalescence of the powder granules during PLS, which results in porosity that undermines the mechanical integrity of printed parts. Moreover, the viscosity of the melt increases due to cross-linking of molecular chains. This, in turn, increases the tensile strength of the printed components at the expense of the percentage elongation at break. Thus, high prolonged processing temperatures decrease the reusability of polymeric materials used in PLS. In this paper, a review of the studies conducted to investigate ways of reducing the effects of high temperature on polymeric powders is presented.
\end{abstract}

\section{Introduction}

Additive manufacturing refers to a set of techniques that enable manufacturing of 3D components from viscous, liquid, or powder materials without the need for tools [1]. As the name suggests, AM involves the addition of layers of material as opposed to conventional subtractive methods of manufacture, where material is removed. The traditional techniques are wasteful as opposed to AM, which in addition enables the manufacture of parts with complex shapes, gives freedom of design, and allows mass customization. A typical process of AM is presented in Figure 1.

Additive manufacturing technologies have gained popularity in the recent past due to their ability to build netshaped components with intricate geometries as opposed to traditional methods. Besides, the technologies can be utilized for manufacture based on different materials, such as metals, metal alloys, polymers, and ceramics [2]. Polymer parts can be manufactured additively through several technologies including stereolithography (STL), selective laser sintering (SLS), fused deposition modelling (FDM), binder jetting, sheet lamination object manufacturing (LOM), and 3D material extrusion [1]. Figure 2 shows typical components manufactured using AM technology. This article focuses on the SLS of polymeric materials, particularly polyamide 12 (PA-12) and polypropylene (PP).

SLS and FDM are the most commonly used AM processes for polymers. The latter technique involves feeding a thin filament of the manufacturing material into a machine where it is melted by a print head [4]. The material is then extruded as shown in Figure 3. The SLS technique involves fusing powder using ultraviolet or carbon laser beams [4]. The difference between the two AM technologies are detailed in Table 1, while the advantages and disadvantages 


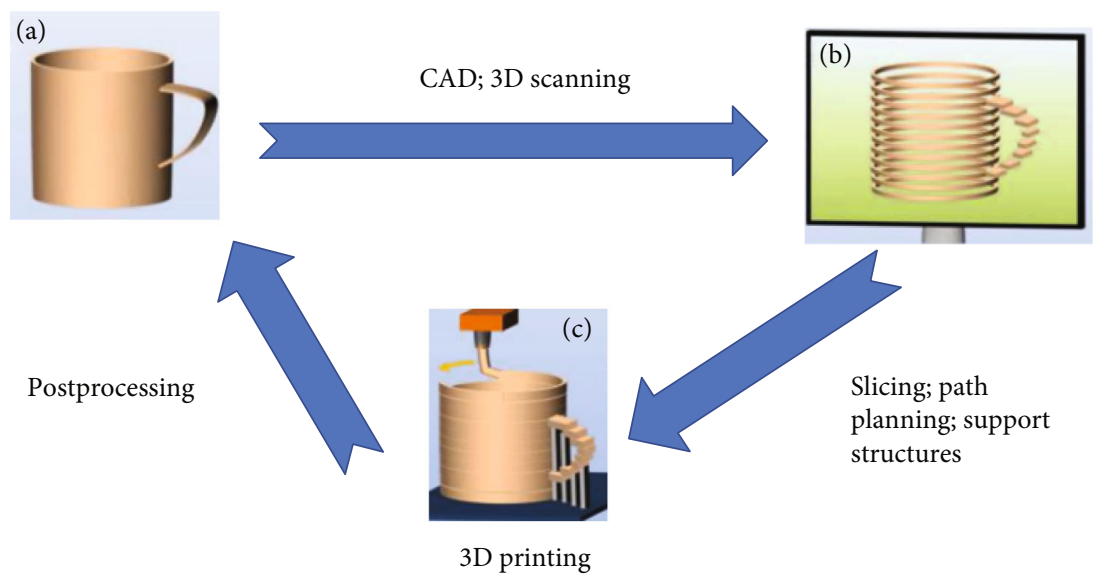

FIGURE 1: Summary of an additive manufacturing process [2].
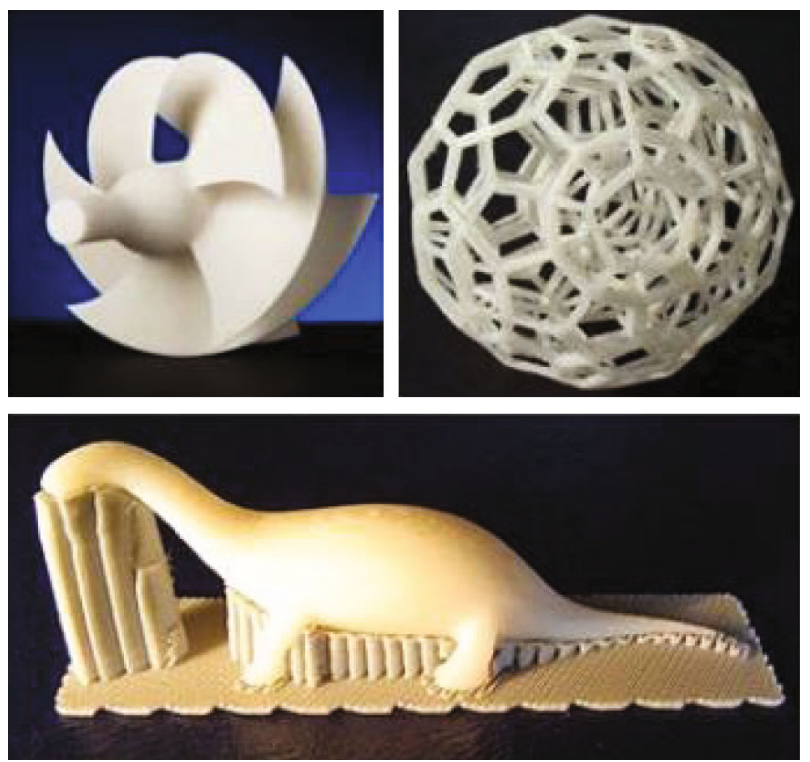

Figure 2: Typical components developed using AM technology [3].

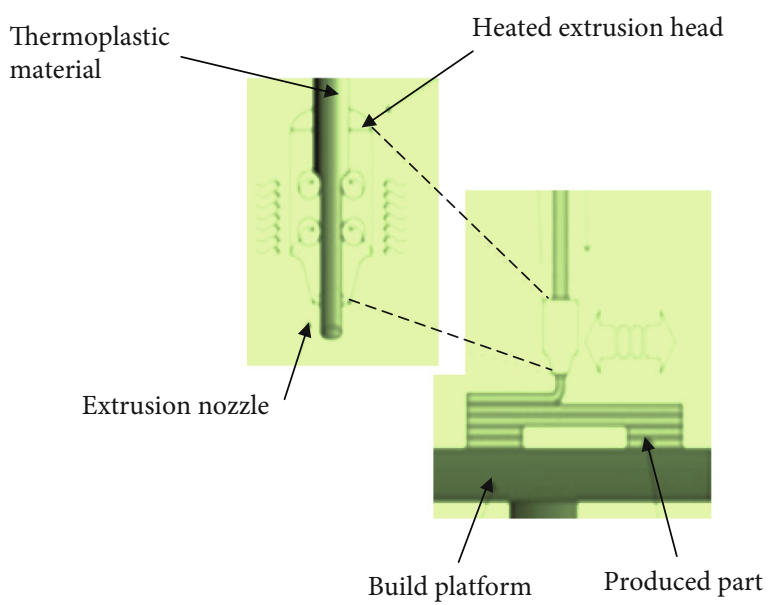

Figure 3: Schematic of the fused deposition method [4]. of the two processes are summarized in Tables 2 and 3, respectively.

The SLS of polymeric materials is commonly referred to as PLS [7]. It is worth noting that only a limited array of polymers has suitable characteristics for PLS. Polyamide and its blends make about $95 \%$ of all the polymers used in PLS AM technology because of their suitable particle size and shape, density, thermal, optical, and rheological properties [7]. Other polymers that are used in PLS include $\mathrm{PP}$, polyether ether ketone (PEEK), polycarbonate (PC), polymethylmethacrylate (PMMA), polystyrene (PS), highdensity polyethene (HDPE), and polybutylene (PB) [8]. There is a need to increase the polymer palette for the PLS process to ensure the advancement of this technology. However, the material range remains limited due to the stringent processing requirements, as well as the challenge of powder degradation due to high processing temperatures. Besides, in PLS, about $80-90$ percent of the powder charge is not used in printing of components [9]. Therefore, there is a need to reuse this high percentage of unused powder in order to avoid wastes and due to its high cost [10]. While this addresses the issue of waste, there is a challenge because of the deterioration of the properties of powder due to high processing temperatures. High processing temperatures are known to affect the mechanical integrity, dimensional accuracy, and surface finish of printed components. Thus, there is a need to sustain, improve, or restore the properties of laser-sintered polymeric powders. This paper presents a review of various studies conducted to determine ways of reducing the deleterious effects of high temperatures on two polymeric materials: PA-12 and PP in the PLS process. The two powders are selected for discussion here because of the predominance use of the first one in PLS and possible alternative use of the second one. It is noted, however, that the ensuing discussion cannot be applied universally to the wide range of polymer powders presently gaining entry into the field of AM, as they differ in constitution and therefore are expected to differ in response to temperature. The review is however useful in providing a basis on which the utility of these other powders can be assessed. 
TABLE 1: A comparison between FDM and SLS AM technologies.

\begin{tabular}{lc}
\hline FDM & SLS \\
\hline $\begin{array}{l}\text { Involves extrusion of a filament } \\
\text { Requires support structures }\end{array}$ & $\begin{array}{c}\text { Involves fusion of powder particles } \\
\text { No need for support structures since the unsintered powder serves } \\
\text { this purpose }\end{array}$ \\
$\begin{array}{l}\text { Suitable for office use since a majority of the printers are desktop-sized } \\
\text { and, thus, require less space. }\end{array}$ & $\begin{array}{c}\text { Most of printers require significant space and are commonly } \\
\text { utilized for industrial applications }\end{array}$ \\
\hline
\end{tabular}

TABle 2: Advantages and Disadvantages of FDM.

\begin{tabular}{lc}
\hline Advantages & Disadvantages \\
\hline $\begin{array}{l}\text { Low or moderate cost of the equipment } \\
\text { Has a wide array of colourful materials for printing }\end{array}$ & $\begin{array}{c}\text { Not suitable for printing sharp edges, thin walls, or acute } \\
\text { angles and, hence suffers some limitation of design } \\
\text { Requires support structures, which affects surface finish } \\
\text { The dimensional and geometrical accuracy is not very } \\
\text { accurate }\end{array}$ \\
$\begin{array}{l}\text { Low or moderate postprocessing cost } \\
\text { Reduced lead time compared to SLS [5] }\end{array}$ & $\begin{array}{r}\text { Difficulties in regulating the build chamber temperature } \\
\text { affects the printed parts }\end{array}$ \\
$\begin{array}{l}\text { Capable of deposition of diverse materials, which include polycarbonate, } \\
\text { acrylonitrile butadiene styrene, and polylactic acid polymers [6] }\end{array}$ & $\begin{array}{c}\text { The tensile strength of printed components is much less than } \\
\text { for injection moulded counterparts [6] } \\
\text { reduces the mechanical strength of printed parts [6] }\end{array}$ \\
\hline
\end{tabular}

TABLE 3: Advantages and disadvantages of SLS.

\begin{tabular}{|c|c|}
\hline Advantages & Disadvantages \\
\hline Does not require support structures & The industrial equipment is expensive \\
\hline $\begin{array}{l}\text { Capable of printing intricately shaped components with a } \\
\text { significantly geometrical accuracy compared to FDM [5] }\end{array}$ & $\begin{array}{c}\text { Has long throughput time, especially for large or geometrically complex } \\
\text { works [5] }\end{array}$ \\
\hline Smooth surfaces are achieved & $\begin{array}{l}\text { Machines must be cleaned thoroughly when changing material to avoid } \\
\text { contamination }\end{array}$ \\
\hline $\begin{array}{l}\text { Parts printed have better tensile strengths than the ones } \\
\text { manufactured using FDM [6] }\end{array}$ & Management of powder inventory is sophisticated \\
\hline \multirow[t]{2}{*}{ Powder can be reused, which saves production cost } & $\begin{array}{l}\text { Limited array of suitable polymeric materials, with polyamide (PA) } \\
\text { contributing to about } 95 \% \text { of all polymers used for SLS [7] }\end{array}$ \\
\hline & $\begin{array}{l}\text { Powder dust is a challenge, which calls for frequent cleaning using } \\
\text { vacuum cleaners }\end{array}$ \\
\hline
\end{tabular}

\section{Polymer Laser Sintering}

Selective laser sintering is used for the manufacture of tooling, prototyping, and functional products from a wide range of materials ranging from metals, metal-alloys, ceramics, to polymers [3]. Metals and metal-alloys are processed using direct metal laser sintering (DMLS) since most of them, such as titanium and its alloys, have high melting points. When the technology is applied solely to polymers, then it is referred to as PLS [9]. In PLS, complex 3D components are manufactured through the coalescence of layers of the materials using a high-energy laser beam. The operation of DMLS and PLS is similar; however, for the latter process, the materials are preheated before the actual printing [6]. A typical PLS set-up is as illustrated in Figure 4.

The polymer laser sintering process is one of the most widely used AM technologies for polymeric materials because of its ability to develop parts with good surface finish,

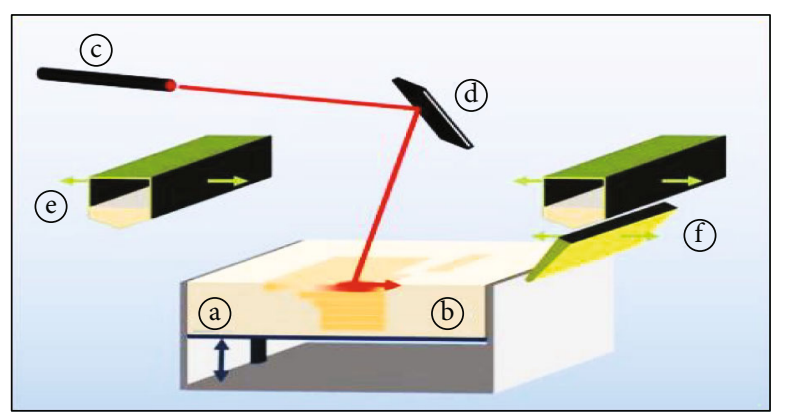

FIgURe 4: Selective laser sintering set-up, (a) build platform, (b) powder bed, (c) laser beam source, (d) focusing system, (e) powder supply chamber, and (f) recoating blade [2].

high dimensional accuracy, sufficient geometrical accuracy, and good mechanical properties $[1,11]$. The process does not require the need for support structures as is the case with 
FDM. This reduces post processing production time and cost. Besides, applying PLS 3D printing to manufacture different pore structures, shapes, and components is much easier than for other AM technologies such as FDM, which is limited due by the use of filaments [12]. Meshed structures are lighter in weight and required less quantities of material, which helps to reduce costs of production [12]. Maconachie et al. further noted that lattice structures possess better acoustic, dielectric, and mechanical properties than their parent materials, which makes them attractive for aerospace applications [11]. In this regard, Liverani et al. illustrated that internal lattice structures have high specific strength and stiffness, and they are easier to analyse $[11,13]$.

The PLS process can be divided into the following three phases.

(1) The process commences by spreading of polymeric powder on the building platform in the building chamber, which is then preheated before using the laser beam to melt the material [7]. For the semicrystalline polymers, the building chamber is preheated to temperatures just below their melting point [8]. The preheating process is performed to ensure that the laser beam is used just to tip the material into a molten state to avoid using excessive energy that would otherwise promote degradation of the powder [7]

(2) The powder is then heated selectively using a laser beam to fuse the particles. After which, the build platform inside the building chamber is lowered by one layer and a new layer of powder material applied. This process continues until a component is fully built

(3) Once the part has been completed, the chamber and the parts are cooled to room temperature in a controlled manner to prevent curling of the parts, which would arise if cooling was rapid [7].

Successful PLS is dependent on the extrinsic and intrinsic properties of powder material. Polymers applicable to SLS should possess suitable intrinsic and extrinsic properties $[14,15]$. Extrinsic properties describe the physical characterizes of the polymers, including powder particle size distribution and morphology. The intrinsic properties of the polymers consist of thermal, rheological, and optical properties [16]. The thermal features of polymeric powders include melting point and sintering window $[14,17]$. The rheological properties include the viscosity and surface tension of the material $[14,17]$. The optical characteristic determines the absorbing behaviour of laser energy $[14,17]$.

A suitable polymeric powder should possess sufficient flow properties to facilitate smooth spreading of the powder by the roller or recoater blade [9]. Nonuniform distribution of powder introduces porosity in the printed parts, which reduces the mechanical integrity of the component. In cases where curling of parts occurs, the recoater blade dislodges the parts from the building chamber, as shown in Figure 5, which stops the printing process [18]. It is worth noting that

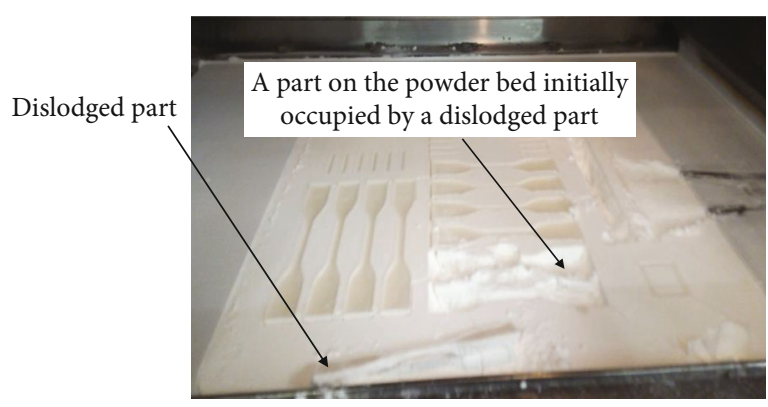

FIGURE 5: Dislodged parts due to curling.

the flowability of polymeric powders is also determined by the particle size and shape. In this regard, previous studies have demonstrated that spherically shaped particles provide the most suitable flowability properties, while the best size distribution ranges between 20 and 100 microns [8, 18]. Moreover, a suitable polymeric material should have low viscosity and low surface tension when molten to ensure adequate coalescence of the powder particles, which ensure sufficient mechanical strength of the built parts [19]. However, the molten material should not sink into the supporting material to prevent rough finish surface, which might warrant postprocessing [9]. Besides, polymers should have a high-temperature degradation point because SLS occurs under high temperatures [17]. Suitable polymers are characterized by a sufficiently wide sintering window, which prevents rapid crystallization of the polymers during processing, which would otherwise encourage shrinkage and part-curling $[8,17]$. Furthermore, suitable polymers should have a narrow melting point region to prevent the use of high laser energy when fusing the powder particles [8]. High laser energy leads to greater degradation of the powder supporting the components being printed, which hampers the recyclability of the material [17]. Besides, the powder must be able to absorb enough energy to ensure the appropriate fusion of the particles. Therefore, appropriate material-properties are essential for lasering sintering of polymers.

Apart from the properties of materials, PLS is subject to process parameters such as building chamber temperature, extraction chamber temperature, power layer thickness, laser power, laser scan speed, hatch distance, and number of scans [20]. These parameters affect printed parts differently. For instance, building and extraction chamber temperatures influence the dimensional accuracy of the printed components. High building and extraction chamber temperature encourage material degradation, whereas low values promote shrinkage, which reduces geometrical, as well as dimensional accuracy. It is necessary to maintain the process temperatures between melting and crystallization points of the material. Material degradation is dependent on the laser energy utilized, where high values enhance deterioration. Conversely, low values discourage particle fusion and, as a result, reduce the mechanical strength of printed parts [17]. The relationship between laser power and other process parameters is presented here as Equation (1), where the symbols $P$ stand for laser power $(\mathrm{J} / \mathrm{s}), E$ laser energy density $\left(\mathrm{J} / \mathrm{mm}^{3}\right)$, 
$V$ laser scan speed $(\mathrm{mm} / \mathrm{s}), H$ hatch distance $(\mathrm{mm})$, and $D$ layer thickness $(\mathrm{mm})$.

$$
E=\frac{P}{V \times H \times D} .
$$

The degradation of polymeric materials can be minimized by using suitable process parameters. However, deterioration is inevitable after repeated use of a given batch of polymer, as well as prolonged processing periods [9]. In this regard, this article reviews some approaches that can be used to restore the properties of the aged polymeric materials, especially for commercial PA-12 and PP powders through powder or process modification.

\section{Thermal Influences on Polyamide 12 and Polypropylene PLS Powder}

During the manufacturing process, the temperature of the building chamber is kept constant to prevent shrinkage of the polymer, which would lead to distortion of the built components [8]. For semicrystalline polymers, the temperature of the process chamber should be maintained between crystallization and melting points [8] The difference between the two temperatures is known as sintering window [8]. In this regard, the sintering window for a suitable PLS polymeric material should be sufficient to promote gradual cooling of the printed components to prevent curling and shrinkage [8]. Marin [17] established that the sintering window of SLS PP powders from Adanc3d Materials $\mathrm{GmbH}$ and Diamond Plastics $\mathrm{GmbH}$ lies between $35.1^{\circ} \mathrm{C}$ and $28.8^{\circ} \mathrm{C}$, respectively [17]. The same researcher found that the sintering window for PA-12 from EOS GmbH Electro Optical Systems is in the range from 32 to $34^{\circ} \mathrm{C}$. Figure 6 provides a summary of the heating profile of polymeric materials during PLS. In the diagram, the symbol $T s$ is the starting temperature, $T_{B}$ the building temperature, $T_{\mathrm{E}}$ the extraction temperature, and $t_{B C}$ the combined building and cooling times. The combined building and cooling times are subject to the distribution, volume, and height of the parts being printed [21]. The curves in Figure 5 show that polymers are subjected to high temperatures during the entire SLS process. This exposure alters the properties of the polymers, which influences the recyclability of the unsintered powder [17].

Polymer laser sintering is a high-temperature process because the building chamber must be maintained at constant temperatures within the sintering windows of specific polymers. In this regard, various researches have shown that exposing polymeric powders surrounding manufactured parts to high temperatures for long periods leads to deterioration of their physical, mechanical, and chemical properties, which in turn hinders reusability of the powders used $[1,7,8,14]$, hence the need to restore the properties of the aged polymeric materials.

The processability and part-properties of PLS printed components, using polymers, are considerably influenced by the viscosity of the material [22]. This occurs at two levels, firstly, the effect of the viscosity of powder on its flowability, which influences its spreading on the powder bed, and sec-

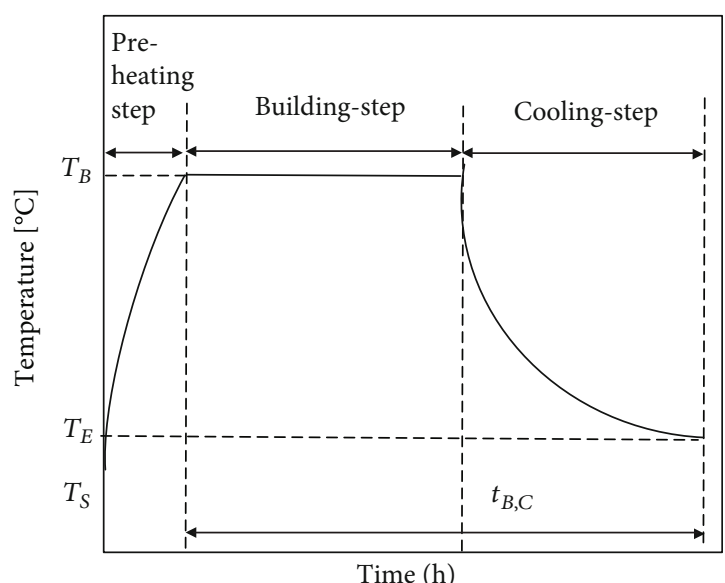

FIGURE 6: The heating profile of polymeric material during SLS [21].

ondly, the viscosity of the powder-melt, which determines the degree of powder particle-fusion, which then determines the mechanical strengths of printed sections [8]. This review, therefore, takes a closer look at the ageing of PA-12 and PP with reference to viscosity.

Lamberti et al. [23] established that viscosity of polymers is subject to their crystallinity. The researchers expressed the viscosity value of polymer melt at a particular temperature as shown by Equation (2), where the symbol $\eta$ stands for viscosity, $T$ temperature, $\eta_{\text {ref }}$ magnitude of reference viscosity, and $a_{T}$ degree of crystallinity at a specific temperature. Considering $\eta_{\text {ref }}$ as a constant, it can be concluded from this equation that the viscosity of polymers at a particular temperature is directly proportional to the degree of crystallinity of the material at the same temperature.

$$
\eta(T)=\eta_{\text {ref }} \cdot a_{\mathrm{T}} .
$$

Different polymeric materials respond differently when subjected to high temperatures. This literature review focuses on PA-12, which forms the bulk of the polymers used in PLS comprising $90-95 \%$ of the total usage [7]. Polypropylene is also investigated because the material forms an appropriate alternative to PA-12 due to its suitable mechanical properties and wide range of applications, especially as a commodity polymer [8].

3.1. Chemical Deterioration of Polymers due to High Temperatures. PA12 and PP experience aging from exposure to high temperatures through several mechanisms including random-chain scission, end-chain scission, chain-stripping, and cross-linking [24]. During scission, carbon-carbon bonds are broken down, which results in the formation of radicals. Random scission happens at any position and leads to the formation of both monomers and oligomers. Conversely, end-chain scission occurs at the end of a chain and results in monomers. Chain-stripping happens when some molecules are removed from a polymer. Lastly, crosslinking leads to overlapping of carbon chains and increases the average molecular weight leading to a rise of the viscosity of the polymers $[7,25]$. Studies by Wegner and Ünlü [26] and 
Wudy et al. [7] indicate that the behaviour of PP and PA-12 is almost similar when subjected to PLS process.

High melt viscosity lowers the coalescence of particles of powder, thus leading to porosity, and in turn undermines the mechanical strength of printed parts [27]. Experiments by Wudy et al. [7] illustrated that the melt flow rate (MFR) of PA-12 decreases with increasing building time, build chamber temperature, and processing cycles. Similarly, the MFR of PP (ROWAK Rolaserit PP) decreases with the number of reuse cycles of the powder [26]. This is because high temperatures cause cross-linking of hydrocarbon chains, which in turn increase the molecular weight of the polymers and leads to an increase of their melt viscosity [28]. Moreover, Wegner and Ünlü [26] established that the melt volume rate (MVR) of PP powder decreases with each reuse cycle. The authors also found that the Hausner number increased from about 1.15 to about 1.25 for the third reuse cycle and hence concluded that the viscosity of powder and melt increased with reuse cycles and would thus affect recyclability of the material.

High processing temperatures increase the viscosity of both PA-12 and PP powders, thus reducing their flowability. Goodridge et al. [8] found that powder with low flowability impacts negatively on the spreading of powder and enhances coalescence of the particles of powder during PLS. Flowability of the polymeric powders is also influenced by the action of the recoater blade, which introduces electrostatic charge to the powder and hence encourages agglomeration thus negatively influencing the spreading of powder [1]. Therefore, high temperatures during PLS processes limit recyclability of polymeric materials, such as PA-12 and PP.

\subsection{Physical and Mechanical Deterioration of Polymers due to} High Temperatures. Polymeric powders used in the PLS process must exhibit a certain level of melt flowability, as this determines the homogeneity of the fusion of the powder particles, which establishes the density and the mechanical strength of the manufactured part [2]. Various studies have shown that both the powder and melt flowability of polymers such as PA-12 and PP decrease with increasing build time and powder bed temperature during the PLS process, which then impact the printed parts $[2,8,14,29-31]$.

In this regard, an increase in building time and temperatures leads to an increase in the crystallinity of PA-12, which affects the built parts $[9,32-35]$. In this respect, a high degree of crystallinity is associated with higher shrinkage of printed components and lower ductility, which affects the dimensional and geometrical accuracy, as well as surface finish of the printed parts [17]. However, the phenomenon reduces chances of porosity, which results in better tensile characteristics of the prints parts [17]. Therefore, it can be concluded that depending on the final use of the printed components, high processing temperatures might either be advantageous or detrimental with respect to crystallinity. However, high crystallinity affects the PLS processability of polymer as high crystallinity results in an increase in molecular weight of polymers $[8,23,25]$ which leads to an increase of viscosity with attendant undesirable reduction in flowability.

A study by Wudy et al. [33] showed polyamide 6 and 66 experience a higher rate of cross-linking at high tempera- tures, which increases molecular weight and as a result the viscosity of the material, which in turn reduces flowability of the materials. The consequence of this is inhomogeneous spreading of powder, which causes porosity inside printed parts, thus reducing the mechanical integrity and quality of the surface finish of printed components [36]. Dotchev et al. found that when polyamide 2200 from the Electro Optical Systems Company (EOS GmbH) is recycled five times without or with small quantities of new material, the produced parts have a rough surface finish [37], a phenomenon referred to as orange peel [22].

Furthermore, the apparent density of PA-12 and PP decreases with increasing temperature, while the relative density of the manufactured components decreases with the reuse cycles $[26,28,38]$. This phenomenon might be attributed to increased viscosity, which causes the introduction of porosity and lower particle-packing due to poor coalescence of powder [27]. Therefore, the mechanical properties of printed parts using PP powder decreases with increasing processing temperature and reuse cycles.

\section{Addressing the Deleterious Effects of Heating on Polymers}

As mentioned previously, PLS subjects polymeric materials to high temperatures, which reduces their reusability due to attendant degradation of their properties. The reuse cycles for PP have not been established. To the contrary, it has been noted that PA-12 material can be reused up to 5 to 8 times before complete degradation $[37,39]$. Based on the available literature on PA-12, the following techniques can be utilized to reduce the deleterious effects of heating on polymers during PLS, based on powder or process modification strategies. The powder enhancement approaches include mixing used powder with fresh powder and adding flow and antistatic agents, whereas the process modification techniques include adopting low-temperature PLS. The ensuing discussion provides an overview of methods that can be utilized to reduce the heat-related effects of degradation of PLS polymers and also the utilization of used PLS powders for FDM.

\subsection{Powder Modification Approaches}

4.1.1. Mixing Used Powder with Fresh Powder. Currently, the most utilized technique for restoring the properties of polymeric powder used in PLS involves mixing aged powder with fresh powder. After sintering, the unsintered powder (powder on the bed, overflow bins, and powder supply bins) is sieved, stored, and used for the next cycle [39]. The cake powder (the powder surrounding the manufactured part) is not reused [37]. Before reusing the powder, quick and simple tests should be performed on the used powder to quantify the level of degradation after every cycle. The most commonly used tests include MFR testing, which determines changes in the rheological behaviour of the powder. The MFR value of the new PA-12 being used in the present work is about $45-50 \mathrm{~g} / 10 \mathrm{~min}$, and it deteriorates from this range with repeated use $[37,10]$. Once the value drops below $18 \mathrm{~g} / 10 \mathrm{~min}$, the powder is discarded [37]. The cut-off MFR 
for PP has not been experimentally established. After testing, the obtained data is used to determine the ratio of virgin to used powder that should be utilized. The ratio of recycled powder in the mixture is referred to as the recyclability of the powder [40].

It is worth noting that other different methods can be employed to characterize aged polymeric powders before reuse in the SLS process. Some of these techniques include differential scanning calorimetry (DSC), thermogravimetric analysis (TGA), laser diffraction analysis, gas pycnometry, and scanning electron microscopy (SEM) testing. Gas pycnometry is a technique that is used to determine the density of a material by measuring the mass and volume of the material [41]. The laser diffraction method is employed to establish the size distribution of powder particles by analysing the angular distribution of scatter of a laser beam allowed to pass in between the particles [42]. Scanning electron microscope technology determines the morphology of powder particles using a beam of electrons to generate images [43]. Differential scanning calorimetry is used to investigate the thermal properties of polymers (melting point $\left(T_{m}\right)$, crystallization $\left(T_{c}\right)$ point, sintering window $\left(T_{m}-T_{c}\right)$, and degree of crystallization) [17]. Thermogravimetric analysis (TGA) is used to determine the temperature of degradation of polymeric materials [44].

The quality of printing products can be determined using mechanical properties or apparent density. The mechanical properties that are commonly determined include ultimate tensile strength, Young's modulus, and percentage elongation. These properties are commonly established using a universal testing machine, as stipulated by various ASTM standards, such as DIN EN ISO 527-1 [30]. The apparent density can be determined by printing cubes of know dimensions and then measuring the masses of the components [30]. Density is then established using Equation (3), where $\rho$ stands for density, $m$ stands for mass, and $v$ stands for volume. The apparent density can also be undertaken using the microcomputed tomography $(\mathrm{CT})$, where the Grey values of the calibration disks are determined, and the actual density calculated using Equation (4) [45]. The CT technique is preferred because it is more accurate than the conventional approach. Moreover, part quality can be determined through measuring surface roughness, where the following parameters, $R a, R z$, and $R q$, are determined using a surface roughness tester. The $R a$ equals to the mean arithmetic deviation of the examined profile, $R z$ is the greatest height of the profile unevenness, and $R q$ represents the depth of the largest profile depression $[46,47]$. Small readings of these three features of surface roughness indicate smooth surfaces. Hence, the values are directly proportional to the surface roughness of a printed part.

$$
\rho=\frac{m}{v}
$$

$$
\text { Actual density }=19.5 . \text { Grey value }+0.20 \text {. }
$$

Most of the producers of $3 \mathrm{D}$ products recycle polymeric powders following recommendations from the manufacturers of the powder. For example, according to 3D Systems,

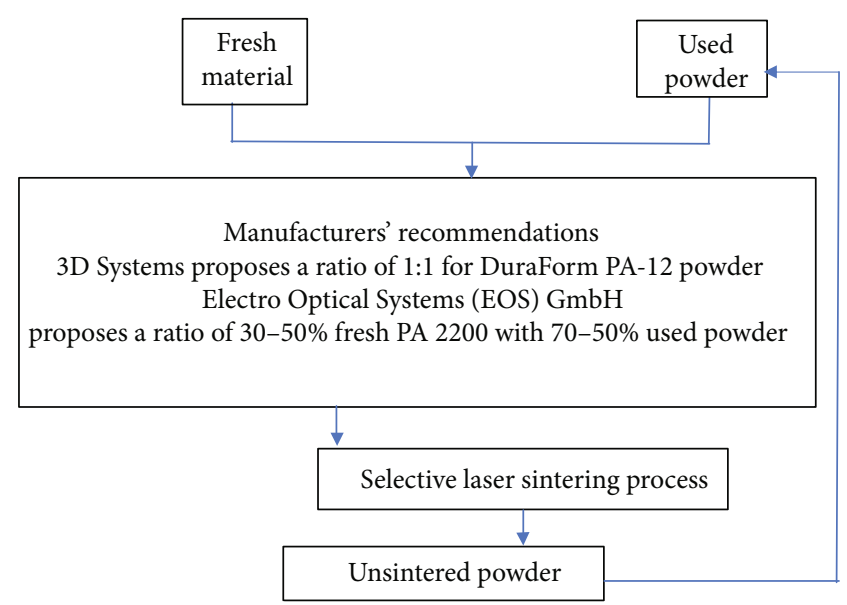

FIGURE 7: Typical recycling process for PLS polymeric powders [37].

used polyamide 12 (Duraform) powder should be mixed with fresh material in a ratio of $1: 1$ whereas EOS $\mathrm{GmbH}$ proposes a ratio of $30-50 \%$ fresh PA-12 grade (PA 2200) powder with $70-50 \%$ used powder [37]. The typical polymeric powder recycling process in PLS is summarized in Figure 7.

Dotchev and Yusoff [37] conducted experiments from which they proposed a flowchart to determine the percentage of used powder and fresh powder that should be used for PA12. They concluded that the prevailing powder recycling practices reduced wastage and costs of production by reusing powder. However, they also observed that the method did not take into account the difference of properties between the used and fresh powders, which could affect the properties of the built parts. Besides, they observed that the redundant powder (a powder that has completely deteriorated due to continued recycling) limited the number of reuse cycles for the polymeric powder. Therefore, the prevailing recycling practices result in powder inventory, which is characterized by inconsistent properties and, in turn, affects the mechanical behaviour of the printed parts [39].

Wegner et al. confirmed that PA 12 deteriorates after polymer laser sintering process [22]. The authors recommended that stable process parameters for the powder can be restored by refreshing used material with about $30-50 \%$ of virgin materials. It was also concluded that even with refreshing rates, unacceptable levels are attained after several cycles. Hence, mixing of fresh and used powders does not entirely solve the problem of polymer aging due to polymer laser sintering.

There is limited research on the reusability of PP powder. Manufacturers, such as Diamond Plastics $\mathrm{GmbH}$, suggests $100 \%$ reusability [48]. This broaches some questions since a study by Wegner and Ünlü [26] showed that the MFR and density of PP reduce with each reuse cycle. PP is expected to show better stability towards laser bed temperature in terms of recycling rate than PA-12 [49]. Therefore, more research needs to be carried out to determine the reuse limit of PP and the most suitable ratio between used and fresh PP powder after each laser sintering cycle.

The method of mixing fresh and used polymeric powder is the most commonly used method of improving PLS polymer materials. The technique is easy to implement, and it is 


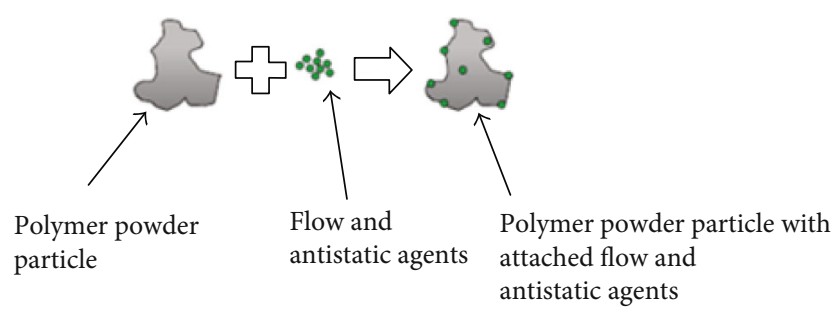

Figure 8: Dry particle coating process [50].
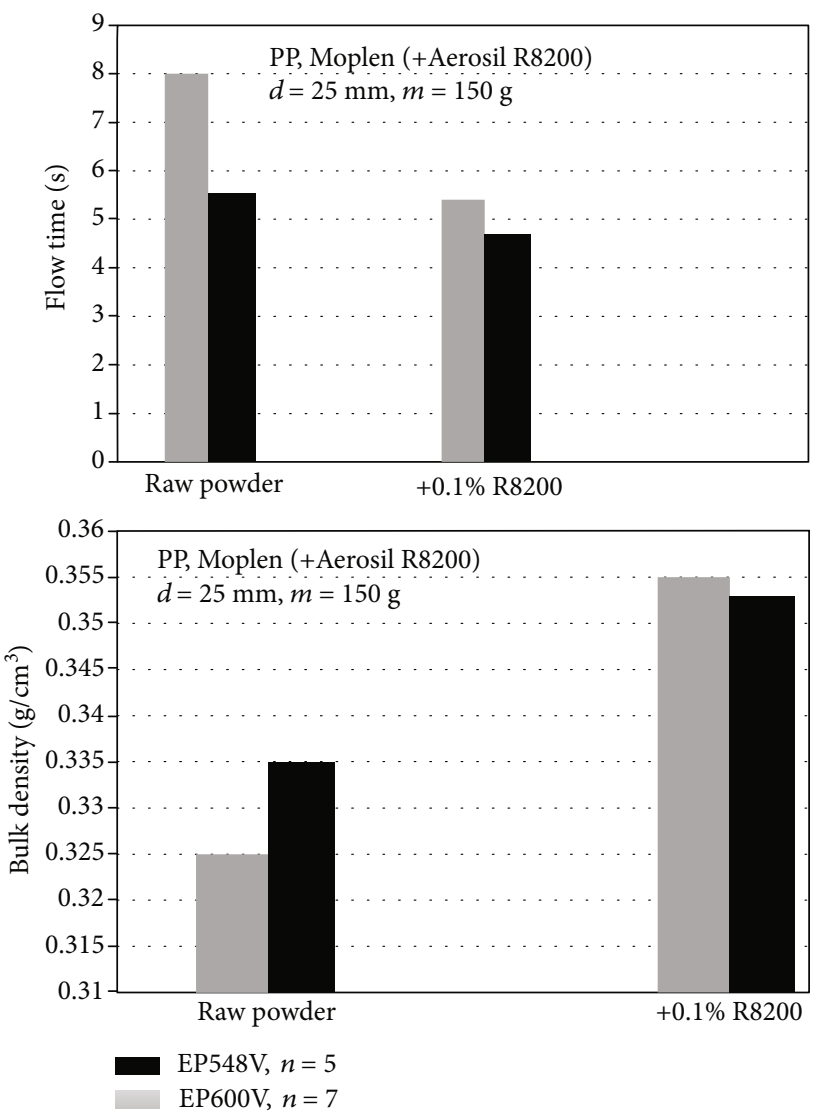

FIGURE 9: The effect of flow and antistatic agents on flow characteristics and bulk density of PP powder [50].

also affordable. However, it requires arduous record keeping ensuring the usage of different batches of powder is carefully tracked. Furthermore, this method is disadvantaged by the accumulation of degraded redundant material after every processing cycle, which reduces the mechanical properties of the printed components.

4.1.2. Adding Flow and Antistatic Agents. The flowability of polymeric powdered materials for PLS can be improved through the use of fillers and additives, such as flow and antistatic agents. Flow agents which are less than $1 \mu \mathrm{m}$ in size are commonly used to this end and include fumed silica, glassy oxides, metallic stearates, or fluoroplastics [50]. Axalta Product Systems, for instance, recommend that their commercial $\mathrm{PP}$ powder be mixed with at least $0.25 \mathrm{wt} \%$ of fumed nanosilica composite $\left(\mathrm{SiO}_{2}\right)$ from the same supplier [50]. These flow
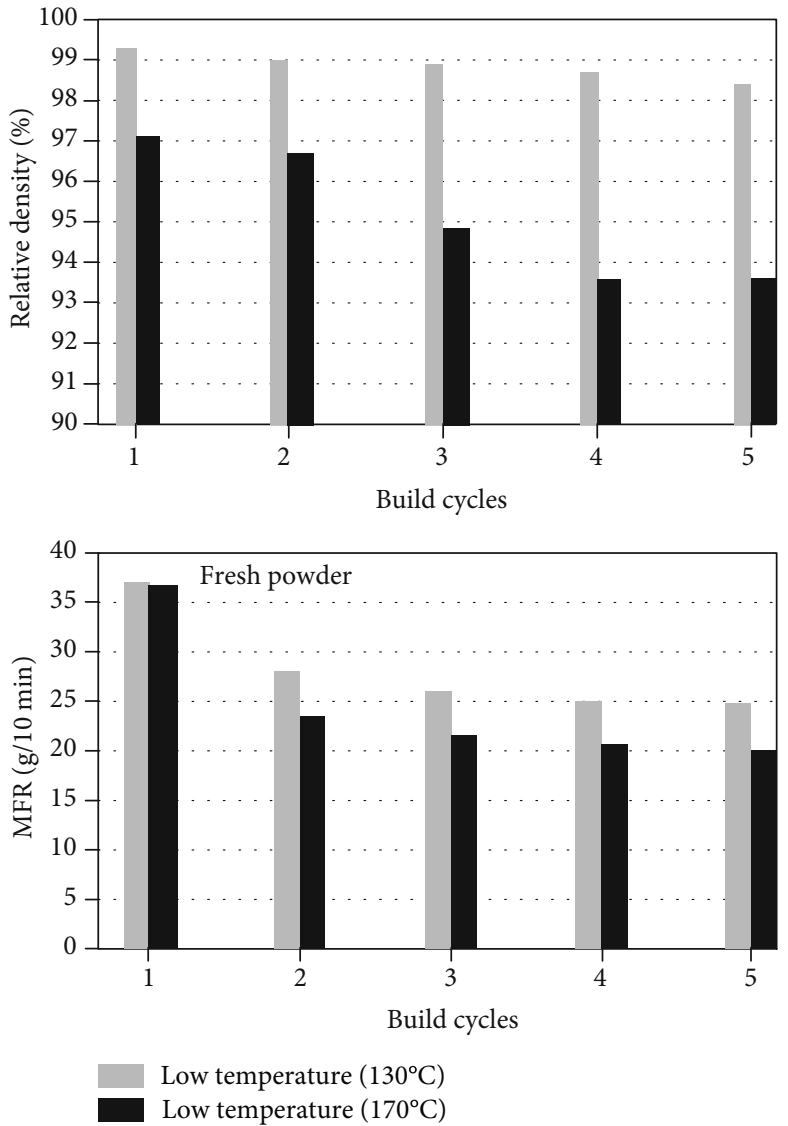

Figure 10: Effect of low- and high-temperature laser sintering on the relative density and melt flow rate of PA-12 [53].

agents are added to powder particles through a dry particle coating process, as illustrated in Figure 8. The flow agents reduce the contact surface area of the powder particles, as shown in Figure 8, which then reduces the adhesion force between the powder particles and promotes smooth powder flow.

Antistatic agents eliminate static charge in plastics and, in turn, reduce the effect of agglomeration of the powder particles, which encourages free-flowing characteristics of the polymer powder [50]. There are various available antistatic agents for PLS polymers including ethylated alkylamines and fatty acid esters, the most commonly used antistatic agents in polyolefins. The antistatic agents can be used in percentages of 0.05 to $1.5 \%$ by weight depending on the application of the powder. Both flow and antistatic agents affect the properties of the primary material, which reduces the mechanical integrity of the printed parts [8].

Lexow and Drummer [50] conducted a study on PP powder and found that the flowability of the powder was increased by the addition of both flow and antistatic agents. Besides, they determined that flow agents increased the bulk density of PP. Details of these two phenomena are presented in Figure 9. However, more research needs to be done to determine the optimum ratio of PP powder to flow and antistatic agents with respect to the number of reuse cycles of the powder and mixing ratios of fresh to used powder. 


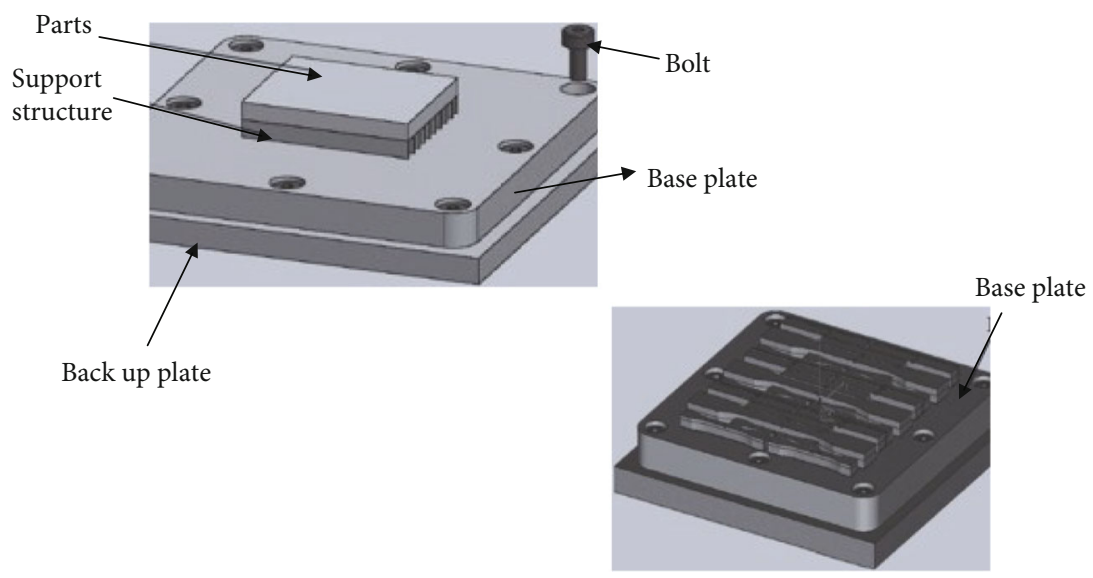

FIgURE 11: Schematic view of an example of a rigid base plate that can be used in low-temperature PLS [53].

The process of using both flow and antistatic agents is associated with both advantages and disadvantages. In this regard, the technique is easy to apply. It also effectively improves the flowability of used polymeric materials. However, the technique fails to enhance the mechanical poperies of the printed parts significantly. The method is also sensitive to the ratio between the powder material and the flow and antistatic agents, which influences the elongation at the breaking point.

\subsection{Process Modification Techniques}

4.2.1. Low-Temperature Selective Laser Sintering. Polymeric Laser Sintering requires that the powder bed temperatures and powder be maintained between recrystallization and melting point of the polymer, to prevent the manufactured components from curling [51]. These conditions are the dominant factors that lead to deterioration of polymeric powders in PLS [52, 53]. Yamauchi et al. [52] proposed low-temperature PLS of polymeric material as an alternative. Such a process does not require the powder bed to be maintained at high temperatures. For example, in lowtemperature laser sintering, the powder bed temperature of PA-12 is maintained at $130^{\circ} \mathrm{C}$, as opposed to the normal process, where temperatures are maintained at about $170^{\circ} \mathrm{C}$, $[8,53]$. A comparative analysis between high- and lowtemperature laser sintering for PA-12 is shown in Figure 10. The rate of deterioration of powder is lower for low-temperature sintering than for high-temperature laser sintering, as shown by changes of powder relative density and melt flow rate with each build cycle in the two cases.

The proposed low-temperature PLS method involves the binding of the parts to a rigid base, as shown in Figure 11, to reduce the effect of curling.

Low-temperature PLS increases the recyclability of polymeric material at the expense of lower mechanical and physical properties of the developed parts due to reduced viscosity and less coalescence of the powder particles. Lowtemperature laser sintering also lowers the design flexibility of PLS since the part is held down to a rigid base. Moreover, different bases need to be constructed for various parts, which is time-consuming and may not be feasible in all instances. There is also a need for posttreatment to prevent curling of the parts once removed from the base plate. In conclusion, low-temperature sintering is linked to the mentioned advantages and disadvantages.

\section{Conclusion}

There is a limited number of polymers materials with suitable properties for use in PLS, which has resulted in a high cost of the feedstock materials and hence the need to recycle the available powder. Recycling of polymers is hindered by the deterioration of the properties of powder due to prolonged thermal stresses associated with the PLS process, thus the need for techniques to alleviate the effects of heat on polymeric materials used in PLS. Mixing of the used powder with fresh powder is the most commonly used method of restoring properties of the used polymeric powder. A lot of research has been conducted to determine the reusability limit and ratio of used and fresh material for PA-12. However, there are limited studies on the same for PP, which calls for studies to fill this gap. Flow and antistatic agents can be used to improve the properties of flowability and bulk density of PP powder used in PLS. However, research needs to be conducted to determine the ratio of a base material (PP) to the flow and antistatic agents based on the deterioration level of powder and mixing ratios of fresh to used powder. The ageing phenomenon of polymeric materials used in PLS can be reduced by the use of low-temperature laser sintering technique. However, this process reduces the homogeneous coalescence of the powder particles, which lowers the mechanical integrity of the developed parts. Furthermore, the low-temperature laser sintering process is timeconsuming and might not be feasible for the manufacturing of articles because different holding base plates are needed for different components. There is also the further need for a heat treatment of built parts before removal from the holding plates to avoid curling. Moreover, while normal PLS leads to a full melt of the polymeric powder, low-temperature PLS is a sintering process which implies a reduction in the densification of the built parts and consequent poorer mechanical and surface properties of the final product. Low-temperature laser sintering has not been tried for PP. 


\section{Conflicts of Interest}

The authors declare that there is no conflict of interest regarding the publication of this paper.

\section{Acknowledgments}

Special gratitude goes to the following journals and researchers, who granted permission to reproduce the diagrams in the article: Walker-Department of Mechanical Engineering Cockrell School of Engineering, Hindawi, and ACS Publications. The research was funded by the Collaborative Program in Additive Manufacturing (Contract No. CSIR-NLC-CPAM-15-MOA-CUT-01).

\section{References}

[1] D. C. Sandeep and D. Chhabra, "Comparison and analysis of different $3 \mathrm{~d}$ printing techniques," International Journal of Latest Trends in Engineering and Technology, vol. 8, no. 4, pp. 264-272, 2017.

[2] S. C. Ligon, R. Liska, J. Stampfl, M. Gurr, and R. Mülhaupt, "Polymers for 3D printing and customized additive manufacturing," Chemical Reviews, vol. 117, no. 15, pp. 10212-10290, 2017.

[3] S. Jasveer and X. Jianbin, "Comparison of different types of 3D printing technologies," International Journal of Scientific and Research Publications (IJSRP), vol. 8, no. 4, 2018.

[4] M. Aydin, "Additive manufacturing: is it a new era for furniture production," Journal of Mechanics Engineering and Automation, vol. 5, no. 1, pp. 38-347, 2015.

[5] C. M. Choudhari and V. D. Patil, "Product development and its comparative analysis by SLA, SLS and FDM rapid prototyping processes," IOP Conference Series: Materials Science and Engineering, vol. 149, no. 1, article 012009, 2016.

[6] C. M. Choudhari and V. D. Patil, "Product Development and its Comparative analysis by SLA, SLS and FDM Rapid Prototyping Processes," International Journal of Latest Trends In Engineering And Technology, vol. 149, no. 4, p. 012009, 2016.

[7] K. Wudy, D. Drummer, and M. Drexler, "Selective laser melting of polyamide 12 -a holistic approach for modelling of the ageing behaviour," in Proceedings of the 5th International Conference on Additive Technologies, vol. 14, pp. 216-221, Cleveland, Ohio, USA, 2014.

[8] R. D. Goodridge, C. J. Tuck, and R. J. M. Hague, "Laser sintering of polyamides and other polymers," Progress in Materials Science, vol. 57, no. 2, pp. 229-267, 2012.

[9] R. Kleijnen, M. Schmid, and K. Wegener, "Production and processing of a spherical polybutylene terephthalate powder for laser sintering," Applied Sciences, vol. 9, no. 7, pp. 13081331, 2019.

[10] A. Pilipović, M. Rujnić-Sokele, and M. Šercer, "Impact of ageing, different share of recycled material and orientation on SLS polyamide product hardness," AIP Conference Proceedings, vol. 1779, no. 1, pp. 10001-10016, 2016.

[11] E. Liverani, A. H. Lutey, A. Fortunato, and A. Ascari, "Characterization of lattice structures for additive manufacturing of lightweight mechanical components," in International Manufacturing Science and Engineering Conference, vol. 50732, pp. 1-18, Los, Angeles, USA, 2017.
[12] T. Maconachie, M. Leary, B. Lozanovski et al., "SLM lattice structures: properties, performance, applications and challenges," Materials \& Design, vol. 183, no. 1, pp. 108137108155, 2019.

[13] W. Tao and M. C. Leu, "Design of lattice structure for additive manufacturing," in 2016 International Symposium on Flexible Automation (ISFA), vol. 1no. 1, pp. 325-332, Cleveland, OH, USA, 2016.

[14] K. Wudy, D. Drummer, and M. Drexler, "Characterization of polymer materials and powders for selective laser melting," AIP Conference Proceedings, vol. 1593, no. 1, pp. 702-707, 2014.

[15] A. Amado, M. Schmid, G. Levy, and K. Wegener, "Advances in SLS powder characterization,” Group, vol. 7, no. 10, pp. 12-25, 2011.

[16] M. B. Sagar and K. Elangovan, "Consolidation \& factors influencing sintering process in polymer powder based additive manufacturing," IOP Conference Series: Materials Science and Engineering, vol. 225, no. 1, article 012075, 2017.

[17] T. M. Marin, Selective laser sintering of polyolefins, M.S. thesis, Tampere Univeristy of Technology, 2017.

[18] M. Schmid and K. Wegener, "Additive manufacturing: polymers applicable for laser sintering (LS)," Procedia Engineering, vol. 149, no. 6, pp. 457-464, 2016.

[19] G. M. Craft, "Characterization of Nylon-12 in a novel additive manufacturing technology, and the rheological and spectroscopic analysis of PEG-starch matrix interactions," vol. 10, no. 1, pp. 10-22, 2018.

[20] H. Zhang and S. LeBlanc, "Processing parameters for selective laser sintering or melting of oxide ceramics," in Additive Manufacturing of High-performance Metals and Alloys Modeling and Optimization, vol. 10, no. 57pp. 1-44, IntechOpen, 2018.

[21] D. Drummer, S. Greiner, M. Zhao, and K. Wudy, "A novel approach for understanding laser sintering of polymers," Additive Manufacturing, vol. 27, no. 12, pp. 379-388, 2019.

[22] A. Wegner, C. Mielicki, T. Grimm, B. Gronhoff, G. Witt, and J. Wortberg, "Determination of robust material qualities and processing conditions for laser sintering of polyamide 12," Polymer Engineering \& Science, vol. 54, no. 7, pp. 1540-1554, 2014.

[23] G. Lamberti, G. W. M. Peters, and G. Titomanlio, "Crystallinity and linear rheological properties of polymers," International Polymer Processing, vol. 22, no. 3, pp. 303-310, 2007.

[24] C. A. Wilkie and M. A. McKinney, "Thermal properties of thermoplastics," in Plastics Flammability Handbook, pp. 5876, Hanser Publisers, 2004.

[25] S. Josupeit, J. Lohn, E. Hermann, M. Gessler, S. Tenbrink, and H. J. Schmid, "Material properties of laser sintered polyamide 12 as function of build cycles using low refresh rates," in Solid Freeform Fabrication Symposium, pp. 770-781, University of Texas at Austin, 2015.

[26] A. Wegner and T. Ünlü, "Powder life cycle analyses for a new polypropylene laser sintering material," in Proceedings of the 27th Annual International Solid Free Fabrication Symposium Additive Manufacturing Conference, pp. 834-846, University of Texas at Austin, USA, 2016.

[27] S. Berretta, Y. Wang, R. Davies, and O. R. Ghita, "Polymer viscosity, particle coalescence and mechanical performance in high-temperature laser sintering," Journal of Materials Science, vol. 51, no. 10, pp. 4778-4794, 2016. 
[28] D. T. Pham, K. D. Dotchev, and W. A. Y. Yusoff, "Deterioration of polyamide powder properties in the laser sintering process," Proceedings of the Institution of Mechanical Engineers, Part C: Journal of Mechanical Engineering Science, vol. 222, no. 11, pp. 2163-2176, 2008.

[29] J. P. Kruth, P. Mercelis, J. Van Vaerenbergh, L. Froyen, and M. Rombouts, "Binding mechanisms in selective laser sintering and selective laser melting," Rapid Prototyping Journal, vol. 11, no. 1, pp. 26-36, 2005.

[30] K. Wudy and D. Drummer, "Aging behaviour of polyamide 12 , interrelation between bulk characteristics and part properties," in Solid Freeform Fabrication Symposium-an Additive Manufacturing Conferenceno. 27, pp. 770-781, Austin, TX, USA, 2016.

[31] I. Flores Ituarte, O. Wiikinkoski, and A. Jansson, "Additive manufacturing of polypropylene: a screening design of experiment using laser-based powder bed fusion," Polymers, vol. 10, no. 12, pp. 1281-1293, 2018.

[32] S. Dadbakhsh, L. Verbelen, O. Verkinderen, D. Strobbe, P. van Puyvelde, and J. P. Kruth, "Effect of PA12 powder reuse on coalescence behaviour and microstructure of SLS parts," European Polymer Journal, vol. 92, pp. 250-262, 2017.

[33] K. Wudy, D. Drummer, F. Kühnlein, and M. Drexler, "Influence of degradation behaviour of polyamide 12 powders in laser sintering process on produced parts," AIP Conference Proceedings, vol. 1593, no. 1, pp. 691-695, 2014.

[34] L. Feng, Y. Wang, and Q. Wei, "PA12 powder recycled from SLS for FDM," Polymers, vol. 11, no. 4, pp. 727-737, 2019.

[35] P. Mägi, A. Krumme, and M. Pohlak, "Material recycling and improvement issues in additive manufacturing," in Proceedings of the 10th International DAAAM Baltic Conference, vol. 10no. 1, pp. 12-13, Tallinn, Estonia, 2015.

[36] S. Berretta, O. Ghita, and K. E. Evans, "Morphology of polymeric powders in laser sintering (LS): from polyamide to new PEEK powders," European Polymer Journal, vol. 59, no. 1, pp. 218-229, 2014.

[37] K. Dotchev and W. Yusoff, "Recycling of polyamide 12 based powders in the laser sintering process," Rapid Prototyping Journal, vol. 15, no. 3, pp. 192-203, 2009.

[38] L. Fang, Y. Wang, and Y. Xu, "Preparation of SLS polypropylene powder by solvent method," Preprint, vol. 1, no. 1, pp. 1-7, 2018.

[39] J. Choren, V. Gervasi, T. Herman, S. Kamara, and J. Mitchell, "SLS powder life study," in Twelfth Annual International Solid Freeform Fabrication Symposium, vol. 12, no. 1pp. 39-45, the University of Texas at Austin, 2001.

[40] Y. Yamauchi, T. Kigure, and T. Niino, "Low-temperature laser sintering of PA powder using fiber laser," Annual International Solid Freeform Fabrication Symposium, vol. 27, no. 1, pp. 2204-2216, 2016.

[41] Y. Khalil, N. Hopkinson, A. Kowalski, and J. P. A. Fairclough, "Characterisation of UHMWPE polymer powder for laser sintering," Materials, vol. 12, no. 21, pp. 3496-3516, 2019.

[42] M. Schmid, A. Amado, and K. Wegener, "Polymer powders for selective laser sintering (SLS)," AIP Conference Proceedings, vol. 1664, no. 1, pp. 1-6, 2015.

[43] W. Zhou, R. Apkarian, Z. L. Wang, and D. Joy, "Fundamentals of scanning electron microscopy (SEM)," Scanning Microscopy for Nanotechnology: Techniques and Applications, vol. 1, no. 1, pp. 1-40, 2007.
[44] C. Schick, "Differential scanning calorimetry (DSC) of semicrystalline polymers," Analytical and Bioanalytical Chemistry, vol. 395, no. 6, pp. 1589-1611, 2009.

[45] A. Du Plessis, M. Meincken, and T. Seifert, "Quantitative determination of density and mass of polymeric materials using microfocus computed tomography," Journal of Nondestructive Evaluation, vol. 32, no. 4, pp. 413-417, 2013.

[46] R. Majchrowski and K. Morawski, "Surface roughness measurements method based on non-contact optoncdt sensor," XXI IMEKO World Congress "Measurement in Research and Industry”, vol. 21, no. 1, pp. 1-7, 2015.

[47] G. Farkas and Á. Drégelyi-Kiss, "Measurement uncertainty of surface roughness measurement," IOP Conference Series: Materials Science and Engineering, vol. 448, no. 1, article 012020, 2018.

[48] "Datasheet for Laser PP CP 60 polypropylene laser sinter powder," October 2019, http://www.diamond-plastics.de/en/ products/laser-pp-cp-60.html.

[49] T. Guillaume, ""Private communications", Global Product Manager, Axalta Product Systems," October 2019, https:// www.axalta.com/corporate/en_US.html.

[50] M. M. Lexow and D. Drummer, "New materials for SLS: the use of antistatic and flow agents," Journal of Powder Technology, vol. 2016, Article ID 4101089, 9 pages, 2016.

[51] M. Schmid, A. Amado, and K. Wegener, "Materials perspective of polymers for additive manufacturing with selective laser sintering," Journal of Materials Research, vol. 29, no. 17, pp. 1824-1832, 2014.

[52] Y. Yamauchi, T. Niino, and T. Kigure, "Influence of process time and geometry on part quality of low-temperature laser sintering," Solid Freeform Fabrication Symposium, vol. 28, no. 1, pp. 1495-1506, 2017.

[53] T. Kigure and T. Niino, "Improvement of recycling rate in laser sintering by low-temperature process," Solid Freeform Fabrication Symposium, vol. 28, no. 1, pp. 550-557, 2017. 